\title{
FORMULATION AND EVALUATION OF BESIFLOXACIN NON-ERODIBLE OCULAR INSERTS
}

\author{
JAYASHRI A. PATIL*, RAVINDRA B. PATIL
}

\author{
D. C. S's A. R. A College of Pharmacy, Nagaon, Dhule
}

Email: jayshreeapatil22@gmail.com

Received: 04 Sep 2021, Revised and Accepted: 18 Oct 2021

\section{ABSTRACT}

Objective: Ocular inserts offer many advantages over conventional dosage forms, like increased ocular residence, the possibility of releasing a drug at a slow and constant rate, accurate dosing, exclusion of preservatives, and increased shelf life. Besifloxacin is a very important drug for the treatment of infectious conjunctivitis. The present study was aimed to formulate and evaluate Besifloxacin Non-Erodible Ocular Insert using Pullulan and polyvinyl pyrrolidone as a drug reservoir, PEG 400 as a plasticizer, and Eudragit RS-100 as a rate-controlling membrane.

Methods: Central composite design was employed to study the effect of independent variables, i.e., effects of Pullulan amount (X1) and PVP (X2) on the dependent variables, i.e., \% moisture absorption and In vitro diffusion rate. After evaluation of all thirteen batches of ocular insert reservoir formulation, BSF2 and BSF4 were selected as a satisfactory formulation and was sandwiched between rate-controlling membrane, which was made up of Eudragit RS-100 (3 and 5\%).

Results: The drug content of all formulations was found to be in the range of 95.33 to $99.89 \%$. In vitro diffusion of Besifloxacin from reservoir formulations (BSF1 to BSF13) was found to be 62.44 to $70.62 \%$. In vitro diffusion rate of an ocular insert of Besifloxacin can offer benefits such as increasing residence time, prolonging drug release in the eye for $24 \mathrm{~h}$. Eudragit RS-100, as a sustained drug release polymer, showed promising sustained released action.

Conclusion: The study concluded that Besifloxacin non-erodible ocular inserts can be successfully developed using Pullulan and polyvinyl pyrrolidone, which will sustain the release of the drug also reduce the frequency of administration, and thereby may help to improve patient compliance.

Keywords: Besifloxacin, Non-erodible ocular insert, Pullulan, PVP, Eudragit RS-100, etc

(C) 2022 The Authors. Published by Innovare Academic Sciences Pvt Ltd. This is an open access article under the CC BY license (https://creativecommons.org/licenses/by/4.0/) DOI: https://dx.doi.org/10.22159/ijap.2022v14i1.43058. Journal homepage: https://innovareacademics.in/journals/index.php/ijap

\section{INTRODUCTION}

Infectious conjunctivitis has a high impact on public health, accounting for more than a third of eye conditions reported by health services worldwide. Bacterial conjunctivitis is an inflammation of the conjunctiva, characterized by persistent mucopurulent discharge and redness of the eye. It is generally a selflimiting disease and usually does not cause permanent loss of vision or structural damage to the eye [1]. Besifloxacin (7-[(3R)-3aminohexahydro-1H-azepin-1-y1]-8-choloro-1-cyclopropyl-6fluoro-1,4-dihydro-4-oxo-3-quinoline carboxylic acid) is a novel, chiral synthetic fluoroquinolone being developed by Bausch and Lomb for the topical treatment of ophthalmic infections. Structurally, besifloxacin has an N-1 cyclo-propyl group, which provides broad-spectrum activity against aerobic bacteria. Besifloxacin inhibits both bacterial DNA gyrase (topoisomerase II) and topoisomerase IV, in contrast to the older fluoroquinolones, which bind more strongly to one of the enzymes. This may minimize resistance because mutations of both enzymes are required for resistance to develop [2]. Besifloxacin is a very important drug for the treatment of infectious conjunctivitis since it presents less occurrence of bacterial resistance than other drugs used for the same purpose and, at the same time, presents great efficacy and tolerability [3]. Besifloxacin is a topical synthetic fluoroquinolone and represents the first chlorofluoroquinolone developed specifically for the topical treatment of ophthalmic infections [4].<smiles>N[C@H]1CCCCN(c2c(F)cc3c(=O)c(C(=O)O)cn(C4CC4)c3c2Cl)C1</smiles>

Fig. 1: Chemical structure of besifloxacin
Extensive investigations have been done for the development of new systems of ophthalmic drug delivery with prolonged retention time on the eye surface, reduced dosing frequency, and improving permeation through trans-corneal layers [5]. Ocular insert seems promising, which improves the efficiencies of the therapy by prolonging the contact time with improved patient compliance. The ocular insert offers many advantages over conventional dosage forms, like increased ocular residence, the possibility of releasing drugs at a slow and constant rate, accurate dosing, and exclusion of preservatives, and increased shelf life $[6,7]$. So the present study aimed to formulate and evaluate ocular inserts of Besifloxacin for sustained action, reduction in the frequency of administration, and greater therapeutic efficacy.

\section{MATERIALS AND METHODS}

\section{Materials}

Besifloxacin was obtained as a generous gift from Glenmark Pharmaceuticals, Mumbai, India. Pullulan was procured from TCI Japan. Polyvinyl pyrrolidone (PVP), PEG 400, and Ethylcellulose (EC $15 \mathrm{cps}$ ) were obtained from SD Fine Chemicals, Mumbai, India, and Eudragit RS100 were provided as gift samples from Aurobindo Pharma Ltd., Hyderabad. All other chemicals used were of analytical grade.

\section{Methods}

\section{Formulation of besifloxacin non-erodible ocular inserts}

The ocular inserts of Besifloxacin were formulated using the solvent casting method with a combination of polymers (Pullulan and PVP) and PEG 400 (w/v of polymer) used as a plasticizer for the uniform strength of insert, as per composition given in table 1 . The required amount of polymers was dissolved in two different beakers in the required quantity of distilled water $(50 \mathrm{ml})$ and stirred on a magnetic stirrer until completely dissolved than both solutions of polymers are mixed and then PEG ( $\mathrm{w} / \mathrm{v}$ of polymer) was added as a plasticizer to the solution under stirring condition. The weighed 
amount of drug $(0.6 \%)$ was added to the above solution and stirred for $1 \mathrm{~h}$ to get uniform dispersion. The solution of polymers was sonicated for $30 \mathrm{~min}$ to remove the air bubbles. After proper mixing, the casting solution is poured into a clean glass Petri dish. The dried films, thus, obtained were cut into circular pieces of definite size (5.5 $\mathrm{mm}$ diameter). The ocular inserts were then wrapped in aluminum foil and were stored in an airtight container (desiccators). In the present study, a Central composite design factorial design was employed to study the effect of independent variables, i.e., effects of Pullulan amount (X1) and PVP (X2) on the dependent variables, i.e., $\%$ moisture absorption and in vitro diffusion rate $[8,9]$. Factorial design of formulated batches is shown in table 1 . As per the provision of Design-Expert software following batches of Ocular Insert were prepared.

Table 1: Composition of reservoir membrane

\begin{tabular}{lllll}
\hline Batch & Drug & Pullulan (mg) & PVP (mg) & PEG 400 (mg) \\
\hline BSF1 & $0.6 \%$ & 7.5 & 1.5 & 250 \\
BSF2 & $0.6 \%$ & 10 & 2 & 250 \\
BSF3 & $0.6 \%$ & 10 & 1 & 250 \\
BSF4 & $0.6 \%$ & 5 & 2 & 250 \\
BSF5 & $0.6 \%$ & 7.5 & 1 & 250 \\
BSF6 & $0.6 \%$ & 7.5 & 1.5 & 250 \\
BSF7 & $0.6 \%$ & 7.5 & 1.5 & 250 \\
BSF8 & $0.6 \%$ & 7.96447 & 0.792893 & 250 \\
BSF9 & $0.6 \%$ & 7.5 & 1.5 & 250 \\
BSF10 & $0.6 \%$ & 11.0355 & 1.5 & 250 \\
BSF11 & $0.6 \%$ & 7.5 & 1.5 & 250 \\
BSF12 & $0.6 \%$ & & 1.5 & 250 \\
BSF13 & $0.6 \%$ & & 2.20711 & \\
\hline
\end{tabular}

\section{Evaluation of besifloxacin reservoir}

\section{Thickness}

The thickness of the insert was determined using a vernier caliper at five separate points of each insert. From each formulation, five randomly selected inserts were tested for their thickness [10].

\section{Uniformity of weight}

From each batch, five inserts were weighed individually using a digital balance. The mean weight of the insert was noted. The percent deviation was calculated from the individual weight of the inserts [11].

\section{Drug content}

Five ocular inserts were taken from each batch and dissolved in $25 \mathrm{ml}$ of isotonic phosphate buffer $\mathrm{pH} 7.4$ into a volumetric flask. One $\mathrm{ml}$ of the above solution was withdrawn and the absorbance was measured by UV-VIS spectrophotometer at $285.6 \mathrm{~nm}$ after suitable dilution [12].

\section{Folding endurance}

Five films of each formulation of size $(20 \times 20 \mathrm{~mm})$ were cut by using a sharp blade. Folding endurance was determined by repeatedly folding a small strip of the film at the same place till it broke. The number of times the film could be folded at the same place without breaking gave the value of folding endurance. A mean of five readings was recorded [13].

\section{Tensile strength determination}

The film was cut into strips $(50 \times 10 \mathrm{~mm})$. Tensile strength and elongation at break were determined by the modified method used by researchers [14]. The apparatus consisted of a base plate with a pulley aligned on it. The film was fixed in a film holder at one end of a base plate and another end was fixed with the help of forceps having a triangular end to keep the film straight during stretching. A thread was tied to the triangular end and passed over the pulley, to which a small pan was attached to hold weights. A small pointer was attached to the thread that travels over the graph paper affixed on the base plate. The weights were gradually added to the pan till the film was broken. The weight necessary to break the film was noted as break force and the simultaneous distance traveled by the pointer on the graph paper indicated the elongation at break [15].

$$
\begin{gathered}
\text { Tensile Strength }=\frac{\text { Break force }}{\text { Cross-sectional area of the sample (mm2) }} \\
\text { Elongation }=\frac{\text { Increase in length at breakpoint }(\mathrm{mm})}{\text { Original Length }} \times 10
\end{gathered}
$$

\section{\% Moisture absorption}

The percentage moisture absorption test was carried out to check the physical stability or integrity of the film at humid condition. The five inserts were taken from each formulation. Individual inserts were weighed and placed in a desiccator containing a saturated solution of aluminum chloride and $84 \%$ humidity was maintained [16]. After three days, the inserts were reweighed. The \% moisture absorption was calculated using the formula:

$$
\begin{gathered}
\% \text { Moisture absorption }=\{(\text { Final weight-Initial Weight }) / \text { Final } \\
\text { Weight }\} \text { X } 100
\end{gathered}
$$

\section{$\%$ Moisture loss}

The percentage moisture loss was carried out to check the integrity of the film at dry conditions. The five inserts from each formulation were taken for study. Inserts were weighed individually and kept in a desiccator containing anhydrous calcium chloride. After three days, the films were reweighed [17]. The percentage moisture loss was calculated using the formula

$\%$ Moisture loss $=\{($ Initial weight-Final Weight $) /$ Initial Weight $\} \times 100$

\section{Surface pH}

The inserts were allowed to swell in a closed Petri dish at room temperature for $30 \mathrm{~min}$ in $0.1 \mathrm{ml}$ of distilled water. "The swollen device was removed and placed under digital $\mathrm{pH}$ meter to determine the surface $\mathrm{pH}$ [18].

\section{In-vitro diffusion study}

The in-vitro diffusion of Besifloxacin from the different formulations was studied using the classical standard cylindrical tube fabricated in the laboratory a simple modification of glass tube of $15 \mathrm{~mm}$ internal diameter and $100 \mathrm{~mm}$ height [19]. The commercial semi-permeable membrane cellophane, pre-soaked overnight in the freshly prepared dissolution medium (isotonic phosphate buffer $\mathrm{pH}$ 7.4), was tied to one end of the open cylinder (open at both sides), which acted as a donor compartment. An ocular insert was placed inside this compartment. The diffusion cell membrane acted as corneal epithelium. The entire surface of the membrane was in contact with the receptor compartment comprising of $25 \mathrm{ml}$ of isotonic phosphate buffer $(\mathrm{pH}$ 7.4) in a $100 \mathrm{ml}$ beaker. The content of the receptor compartment was stirred continuously using a magnetic stirrer and the temperature was maintained at $37^{\circ} \pm 0.5{ }^{\circ} \mathrm{C}$. At specific time intervals, $1 \mathrm{ml}$ aliquot of sample was withdrawn from the receptor compartment and replaced with fresh buffer solution. The aliquot was analyzed for the drug content using UV-VIS spectrophotometer at 
determined wavelength after appropriate dilutions against reference using isotonic phosphate buffer $\mathrm{pH} 7.4$ as blank [20].

\section{Release kinetics}

To understand the mechanism and kinetics of drug release, the results of the in vitro drug release study were fitted with various kinetic equations namely zero-order (\% release vs. t), first-order $(\log \%$ unreleased vs. t), Higuchi matrix (\% release versus square root of time). To define a model which will represent a better fit for the formulation, drug release data further analyzed by Korsmeyer Pappas equation, $\mathrm{r}^{2}$ were calculated for the linear curves obtained by regression analysis of the above plots [21].

\section{Formulation of rate-controlling membrane}

Rate controlling membrane was prepared using two different concentrations of Eudragit RS-100 (4\% and 6\%) and employing dibutyl phthalate as a plasticizer. Dibutyl phthalate was used in the concentration of $30 \% \mathrm{w} / \mathrm{w}$ based on the weight of the dry polymer. The ethylcellulose was dissolved in acetone $(10 \mathrm{ml})$ and dibutyl phthalate was added as a plasticizer to this solution under stirring on the magnetic stirrer. After proper mixing, the casting solution (5 $\mathrm{ml}$ ) was poured into a clean glass petri dish and covered with an inverted funnel to allow slow and uniform evaporation of solvent at room temperature. After drying at room temperature, circular rings of $10 \mathrm{~mm}$ diameter were cut using a cork borer and used to seal both the sides of the drug reservoir to control the release of drug from the periphery [22, 23]. The compositions of the rate-controlling membrane of ethyl cellulose are shown in table 2.

Table 2: Composition of rate controlling membrane of eudragit RS-100

\begin{tabular}{lll}
\hline Ingredients & EG1 & EG2 \\
\hline Eudragit RS-100 & $3 \%$ & $5 \%$ \\
Dibutyl phthalate & $30 \% \mathrm{w} / \mathrm{w}$ & $30 \% \mathrm{w} / \mathrm{w}$ \\
Acetone & $10 \mathrm{ml}$ & $10 \mathrm{ml}$ \\
\hline
\end{tabular}

Preparation of drug reservoir Sandwich between two ratecontrolling membranes

A drug reservoir sandwich between two rate-controlling membranes was prepared by sealing both sides of the drug reservoir $(8 \mathrm{~mm}$ diameter) with the rate-controlling membrane (10 $\mathrm{mm}$ diameter) to provide controlled release of drug from the periphery. The two ratecontrolling membranes containing reservoir films between them were placed over a beaker saturated with acetone vapors for 3-5 min. This procedure resulted in sealing the two rate-controlling membranes containing the drug reservoir film between them. The ocular insert was then stored in an airtight container (desiccator) [24]. The compositions of the drug reservoir with a rate-controlling membrane are shown in table 3.

Table 3: Composition of drug reservoir sandwich between two rate-controlling membranes

\begin{tabular}{llll}
\hline Batch & Drug reservoir & Rate controlling membrane \\
\cline { 2 - 3 } & Pullulan (mg) & PVP (mg) & Eudragit RS-100 \\
\hline F1 & 5 & 2 & $3 \%$ \\
F2 & 10 & 2 & $3 \%$ \\
F3 & 5 & 2 & $5 \%$ \\
F4 & 10 & 2 & $5 \%$ \\
\hline
\end{tabular}

Evaluation of drug reservoir sandwich between two ratecontrolling membranes

Drug reservoir sandwich between two rate-controlling membranes was evaluated for uniformity of thickness, uniformity of weight, \% moisture absorption, \% moisture loss, surface $\mathrm{pH}$, in vitro diffusion study, and release kinetics as per said procedure [25-27].

\section{RESULTS AND DISCUSSION}

\section{Evaluation of besifloxacin reservoir}

Results of the evaluation of the Besifloxacin reservoir are shown in table 4. The thickness of formulations (BSF1 to BSF13) was found to be in the range of $0.237 \mathrm{~mm}$ to $0.275 \mathrm{~mm}$ as shown in the table 4 . The uniformity in thickness of all formulations ensured that the solvent casting method is suitable for the preparation of ocular inserts [28]. The \% deviation in weight of all formulations was found to be in the range of \pm 0.22 to 0.62 . The uniformity of the weights of the films indicated the good distribution of the drug, polymer, and plasticizer. It was observed that the weight of the inserts increased with the increasing total polymer concentration.

The drug content of all formulations was found to be in the range of 95.33 to $99.89 \%$. It showed a uniform distribution of the drug in all formulations. Folding endurance of all formulations was found to be in the range of 75 to 124 . The folding endurance test results indicated that the inserts would not break and maintain their integrity with general folding when applied. The highest folding endurance was obtained for formulation BSF2, BSF12, and BSF13. Folding endurance increased with the increase in the concentration of polymers [29].

Table 4: Evaluation of besifloxacin reservoir

\begin{tabular}{|c|c|c|c|c|c|c|c|c|}
\hline Batch & $\begin{array}{l}\text { Thickness } \\
\text { (mm) }\end{array}$ & $\begin{array}{l}\text { Weight variation } \\
\text { (\% deviation) }\end{array}$ & $\begin{array}{l}\text { Drug } \\
\text { content (\%) }\end{array}$ & $\begin{array}{l}\text { Folding } \\
\text { endurance }\end{array}$ & $\begin{array}{l}\text { Tensile strength } \\
\mathrm{g} / \mathrm{mm}^{2}\end{array}$ & $\begin{array}{l}\text { \% Moisture } \\
\text { absorption }\end{array}$ & $\begin{array}{l}\% \text { Moisture } \\
\text { loss }\end{array}$ & $\begin{array}{l}\text { Surface } \\
\text { pH }\end{array}$ \\
\hline BSF1 & $0.268 \pm 0.030$ & $0.43 \pm 0.021$ & $97.63 \pm 1.21$ & $98 \pm 2.31$ & $0.528 \pm 0.015$ & $5.56 \pm 0.058$ & $6.79 \pm 0.98$ & $6.23 \pm 0.88$ \\
\hline BSF2 & $0.254 \pm 0.015$ & $0.35 \pm 0.013$ & $98.42 \pm 1.63$ & $112 \pm 1.98$ & $0.762 \pm 0.052$ & $7.02 \pm 0.042$ & $9.51 \pm 0.69$ & $6.78 \pm 0.65$ \\
\hline BSF3 & $0.237 \pm 0.020$ & $0.49 \pm 0.034$ & $96.48 \pm 1.32$ & $104 \pm 2.36$ & $0.724 \pm 0.036$ & $6.68 \pm 0.062$ & $7.63 \pm 0.48$ & $7.23 \pm 0.38$ \\
\hline BSF4 & $0.246 \pm 0.025$ & $0.31 \pm 0.016$ & $95.33 \pm 1.62$ & $84 \pm 1.52$ & $0.429 \pm 0.048$ & $4.62 \pm 0.018$ & $5.96 \pm 0.37$ & $6.96 \pm 0.91$ \\
\hline BSF5 & $0.281 \pm 0.024$ & $0.52 \pm 0.029$ & $96.78 \pm 1.28$ & $81 \pm 2.05$ & $0.418 \pm 0.098$ & $4.57 \pm 0.063$ & $6.42 \pm 0.45$ & $7.58 \pm 0.83$ \\
\hline BSF6 & $0.266 \pm 0.032$ & $0.46 \pm 0.037$ & $98.67 \pm 1.69$ & $97 \pm 1.68$ & $0.563 \pm 0.047$ & $5.24 \pm 0.049$ & $7.83 \pm 0.67$ & $6.92 \pm 0.29$ \\
\hline BSF7 & $0.243 \pm 0.042$ & $0.39 \pm 0.029$ & $99.42 \pm 1.37$ & $99 \pm 1.49$ & $0.528 \pm 0.066$ & $5.51 \pm 0.025$ & $7.63 \pm 0.38$ & $7.45 \pm 0.58$ \\
\hline BSF8 & $0.272 \pm 0.036$ & $0.22 \pm 0.33$ & $98.39 \pm 1.58$ & $89 \pm 2.05$ & $0.393 \pm 0.042$ & $5.12 \pm 0.021$ & $6.89 \pm 0.47$ & $7.14 \pm 0.33$ \\
\hline BSF9 & $0.263 \pm 0.029$ & $0.62 \pm 0.062$ & $97.41 \pm 1.74$ & $75 \pm 1.52$ & $0.357 \pm 0.068$ & $4.22 \pm 0.062$ & $5.67 \pm 0.82$ & $6.68 \pm 0.69$ \\
\hline BSF10 & $0.274 \pm 0.031$ & $0.44 \pm 0.042$ & $98.62 \pm 1.26$ & $96 \pm 1.09$ & $0.496 \pm 0.097$ & $5.43 \pm 0.043$ & $6.79 \pm 0.69$ & $6.59 \pm 0.53$ \\
\hline BSF11 & $0.269 \pm 0.043$ & $0.38 \pm 0.038$ & $98.79 \pm 1.98$ & $102 \pm 2.08$ & $0.572 \pm 0.063$ & $5.58 \pm 0.091$ & $6.91 \pm 0.82$ & $7.41 \pm 0.48$ \\
\hline BSF12 & $0.275 \pm 0.022$ & $0.51 \pm 0.033$ & $99.67 \pm 0.98$ & $124 \pm 1.96$ & $0.804 \pm 0.044$ & $7.35 \pm 0.058$ & $8.94 \pm 0.55$ & $7.23 \pm 0.52$ \\
\hline BSF13 & $0.272 \pm 0.039$ & $0.49 \pm 0.010$ & $99.89 \pm 1.02$ & $113 \pm 2.06$ & $0.618 \pm 0.053$ & $6.18 \pm 0.063$ & $7.82 \pm 0.61$ & $7.51 \pm 0.76$ \\
\hline
\end{tabular}

All values represent mean \pm standard deviation $(n=3)$ 
The tensile strength was found to be in the range of 0.357 to 0.762 $\mathrm{g} / \mathrm{mm}^{2}$. From the results, it was found that tensile strength increases with an increase in the concentration of polymers. \% Moisture absorption of all batches was found to be in the range of 4.22 to 7.35. Results showed that as polymer concentration increases; the percentage of moisture absorption also increases as polymers are more hydrophilic. Moreover, in humid conditions increase in moisture absorption was observed without affecting the physical appearance of ocular inserts [30]. Results of \% moisture loss are shown in table 4. Results showed that the presence of PVP increases the \% moisture loss. Formulation BSF2, BSF12, and BSF13 showed high moisture loss may be due to less hindrance offered by pullulan and PVP [31]. The surface $\mathrm{pH}$ of all batches was found to be between 6.23 to 7.51. Results indicate that the prepared inserts would not alter the $\mathrm{pH}$ of the tear fluid in the eye [32].

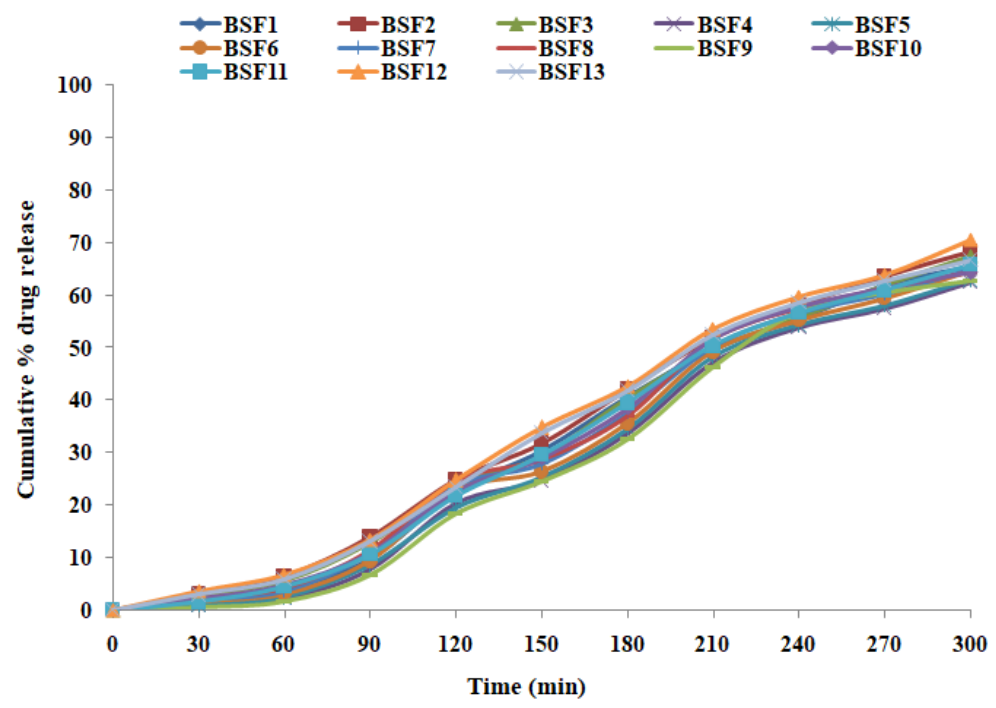

Fig. 2: In vitro diffusion of besifloxacin from reservoir formulations (BSF1 to BSF13)

\section{In vitro diffusion study}

In vitro diffusion of Besifloxacin from reservoir formulations (BSF1 to BSF13) was found to be 62.44 to $70.62 \%$. All the formulations were best fitted into Korsmeyer-Peppas equation and values for ' $n$ ' (diffusion exponent) were $>0.94$, indicating super case II type of release of drug from ocular inserts reservoir. This indicates that drug release is by the non-Fickian mechanism [33].

\section{Central composite design}

Fit summary

Table 5: Response 1: \% moisture absorption

\begin{tabular}{llllll}
\hline Source & Sequential p-value & Lack of Fit p-value & Adjusted $\mathbf{R}^{\mathbf{2}}$ & \multicolumn{2}{c}{${\text { Predicted } \mathbf{R}^{\mathbf{2}}}$} \\
\hline Linear & $<0.0001$ & 0.1247 & 0.9481 & 0.9235 & Suggested \\
2FI & 0.5332 & 0.1044 & 0.9449 & 0.8911 & \\
Quadratic & 0.0961 & 0.1799 & 0.9637 & 0.8882 & \\
Cubic & 0.0626 & 0.9616 & 0.9832 & 0.9888 & Aliased \\
\hline
\end{tabular}

ANOVA for linear model

Table 6: Response 1: \% moisture absorption

\begin{tabular}{llllll}
\hline Source & Sum of squares & df & Mean square & F-value & p-value \\
\hline Model & 10.43 & 2 & 5.21 & 110.54 & 211.63 \\
A-Pullulan & 9.98 & 1 & 9.98 & 9.46 & $<0.0001$ \\
B-PVP & 0.4461 & 1 & 0.4461 & 3.46 & 0.0117 \\
Residual & 0.4717 & 10 & 0.0472 & & 0.1247 \\
Lack of Fit & 0.3956 & 6 & 0.0659 & & not significant \\
Pure Error & 0.0761 & 4 & 0.0190 & & \\
Cor Total & 10.90 & 12 & & & \\
\hline
\end{tabular}

The Model F-value of 110.54 implies the model is significant. There is only a $0.01 \%$ chance that an F-value this large could occur due to noise.

P-values less than 0.0500 indicate model terms are significant. In this case A, B are significant model terms. Values greater than 0.1000 indicate the model terms are not significant. If there are many insignificant model terms (not counting those required to support hierarchy), model reduction may improve your model.

The Lack of Fit F-value of 3.46 implies the Lack of Fit is not significant relative to the pure error. There is a $12.47 \%$ chance that a Lack of Fit F-value this large could occur due to noise. Nonsignificant lack of fit is good--we want the model to fit. 
The Predicted $R^{2}$ of 0.9235 is in reasonable agreement with the Adjusted $\mathrm{R}^{2}$ of 0.9481 ; i.e. the difference is less than 0.2 .

Adeq Precision measures the signal-to-noise ratio. A ratio greater than 4 is desirable. Your ratio of 30.283 indicates an adequate signal. This model can be used to navigate the design space.

The coefficient estimate represents the expected change in response per unit change in factor value when all remaining factors are held constant. The intercept in an orthogonal design is the overall average response of all the runs. The coefficients are adjustments around that average based on the factor settings. When the factors are orthogonal the VIFs are 1; VIFs greater than 1 indicate multi-co linearity; the higher the VIF the more severe the correlation of factors. As a rough rule, VIFs less than 10 are tolerable. Final Equation in Terms of Coded Factors is as follows:

$\%$ moisture absorption $=+5.62+1.12 \mathrm{~A}+0.2361 \mathrm{~B}$

The equation in terms of coded factors can be used to make predictions about the response for given levels of each factor. By default, the high levels of the factors are coded as +1 and the low levels are coded as-1. The coded equation is useful for identifying the relative impact of the factors by comparing the factor coefficients.

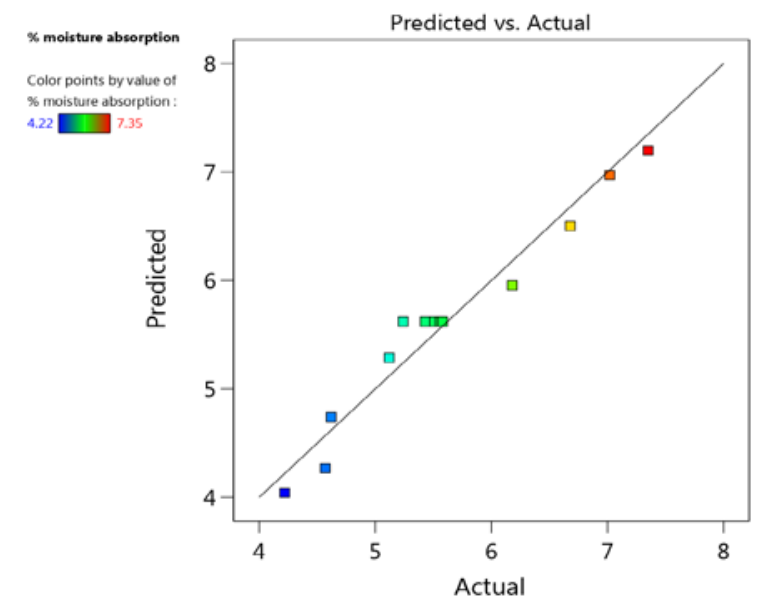

Fig. 3: Predicted Vs actual values for $\%$ moisture absorption

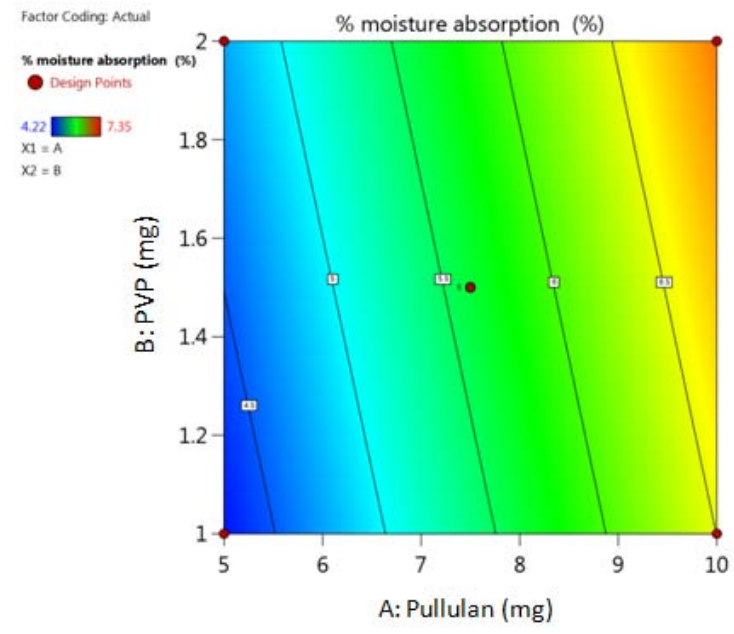

Fig. 4: Counter plot showing the effect of variables on \% moisture absorption

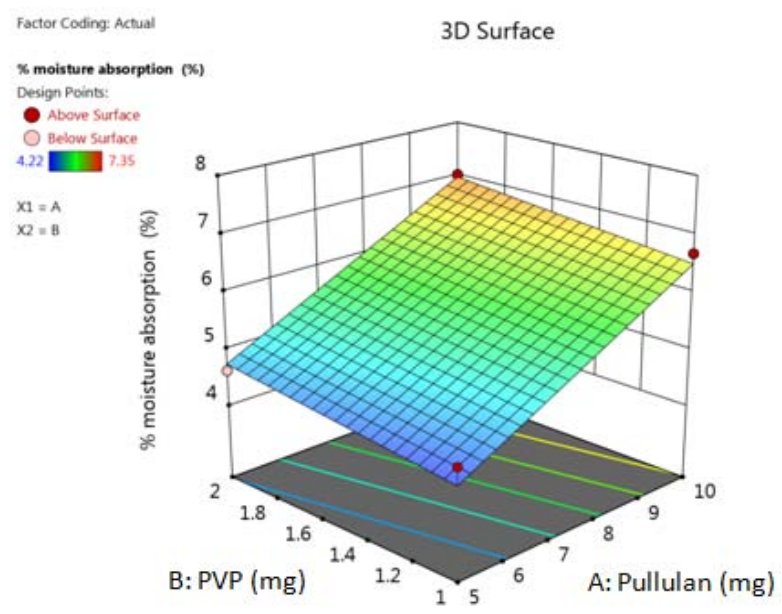

Fig. 5: Response surface plot showing the effect of variables on $\%$ moisture absorption

Fit summary

Table 7: Response 2: In vitro diffusion rate

\begin{tabular}{llllll}
\hline Source & Sequential p-value & Lack of Fit p-value & ${\text { Adjusted } \mathbf{R}^{\mathbf{2}}}$ & Predicted R $^{\mathbf{2}}$ \\
\hline Linear & $<\mathbf{0 . 0 0 0 1}$ & $\mathbf{0 . 1 7 2 7}$ & $\mathbf{0 . 8 7 3 4}$ & $\mathbf{0 . 8 0 1 2}$ & Suggested \\
\hline 2FI & 0.5005 & 0.1481 & 0.8666 & 0.7750 & \\
Quadratic & 0.1835 & 0.1835 & 0.8944 & 0.6758 & Aliased \\
Cubic & 0.3989 & 0.1065 & 0.8976 & -0.4482 & \\
\hline
\end{tabular}

\section{ANOVA for linear model}

Table 8: Response 2: in vitro diffusion rate

\begin{tabular}{lllllll}
\hline Source & Sum of squares & df & Mean square & F-value & p-value & significant \\
\hline Model & 59.80 & 2 & 29.90 & 42.39 & $<0.0001$ & \\
A-Pullulan & 58.07 & 1 & 58.07 & 82.34 & 0.0001 & not significant \\
B-PVP & 1.73 & 1 & 1.73 & & & \\
Residual & 7.05 & 10 & 0.7053 & 2.45 & 0.1727 & \\
Lack of Fit & 5.68 & 6 & 0.9466 & & & \\
Pure Error & 1.37 & 4 & 0.3432 & & & \\
Cor Total & 66.85 & 12 & & & & \\
\hline
\end{tabular}

The Model F-value of 42.39 implies the model is significant. There is only a $0.01 \%$ chance that an F-value this large could occur due to noise.
P-values less than 0.0500 indicate model terms are significant. In this case, A is a significant model term. Values greater than 0.1000 indicate the model terms are not significant. If there are many 
insignificant model terms (not counting those required to support hierarchy), model reduction may improve your model.

The Lack of Fit F-value of 2.76 implies the Lack of Fit is not significant relative to the pure error. There is a $17.27 \%$ chance that a Lack of Fit F-value this large could occur due to noise. Nonsignificant lack of fit is good--we want the model to fit.

The Predicted $\mathrm{R}^{2}$ of 0.8012 is in reasonable agreement with the Adjusted $\mathrm{R}^{2}$ of 0.8734 ; i.e. the difference is less than 0.2 .

Adeq Precision measures the signal-to-noise ratio. A ratio greater than 4 is desirable. Your ratio of 18.889 indicates an adequate signal. This model can be used to navigate the design space.

The coefficient estimate represents the expected change in response per unit change in factor value when all remaining factors are held constant. The intercept in an orthogonal design is the overall average response of all the runs. The coefficients are adjustments around that average based on the factor settings. When the factors are orthogonal the VIFs are 1; VIFs greater than 1 indicate multi-co linearity; the higher the VIF, the more severe the correlation of factors. As a rough rule, VIFs less than 10 are tolerable. Final Equation in Terms of Coded Factors is as follows:

\section{In vitro diffusion rate $=+65.44+2.69 \mathrm{~A}+0.4648 \mathrm{~B}$}

The equation in terms of coded factors can be used to make predictions about the response for given levels of each factor. By default, the high levels of the factors are coded as +1 and the low levels are coded as- 1 . The coded equation is useful for identifying the relative impact of the factors by comparing the factor coefficients.

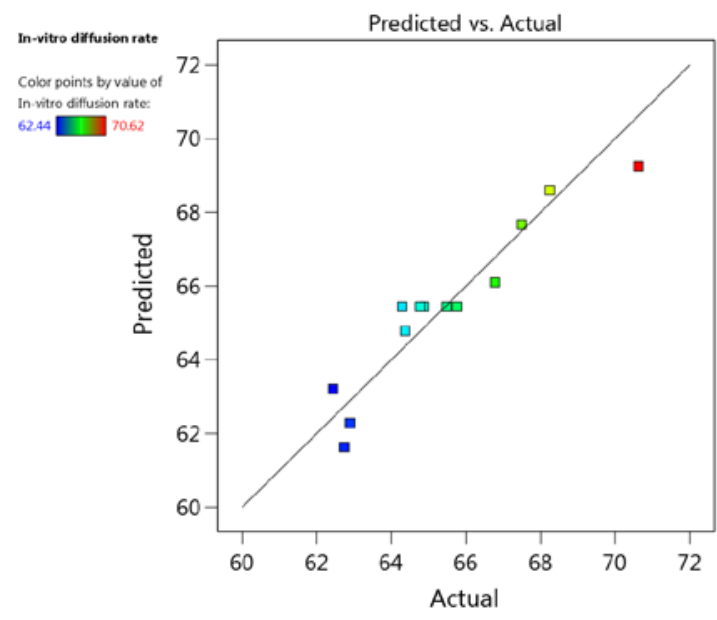

Fig. 6: Predicted Vs actual values for in vitro diffusion rate

Evaluation of drug reservoir sandwich between two ratecontrolling membranes

From the results of an evaluation of the ocular insert of Besifloxacin sandwiched between two rate-controlling membranes, it was found that; thickness of the final ocular insert was increased up to 0.347 to $0.387 \mathrm{~mm}$ as compared to the thickness of the reservoir. Not many weight variations were found between all batches. \% Moisture absorption was found to be 4.86 to 5.83 , which is less as compared to ocular insert reservoir. It may be due to the reservoir sandwich between rate-controlling membranes. The surface $\mathrm{pH}$ of all batches was found to be between 6.24 to 7.42 , which would not alter the $\mathrm{pH}$ of the tear fluid in the eye as the $\mathrm{pH}$ is within the acceptable ocular range.

\section{In vitro diffusion rate}

The in vitro diffusion rate of the ocular insert of Besifloxacin (sandwich between two rate-controlling membranes) was determined for $24 \mathrm{~h}$ and it was compared with the reservoir formulation BSF2 and BSF4. Results are shown in fig. 9.

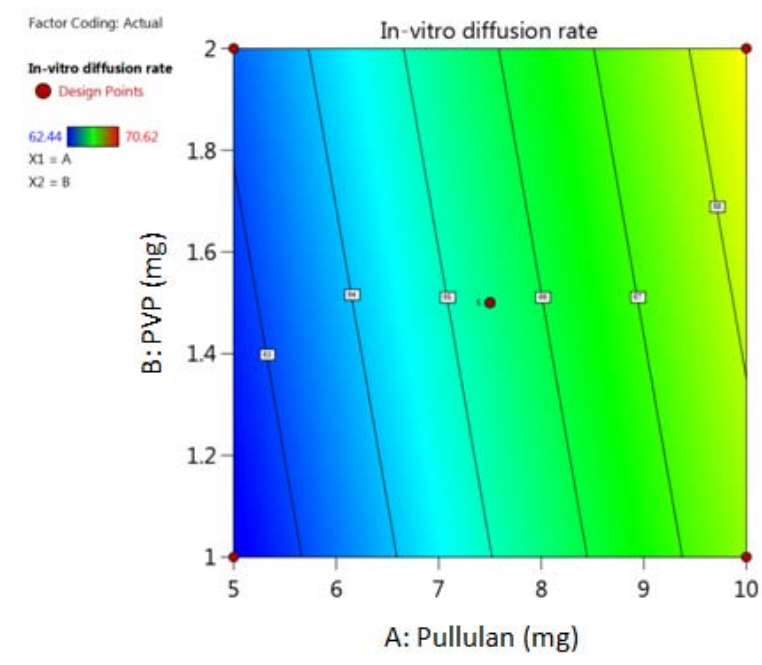

Fig. 7: Counter plot showing the effect of variables on In vitro diffusion rate

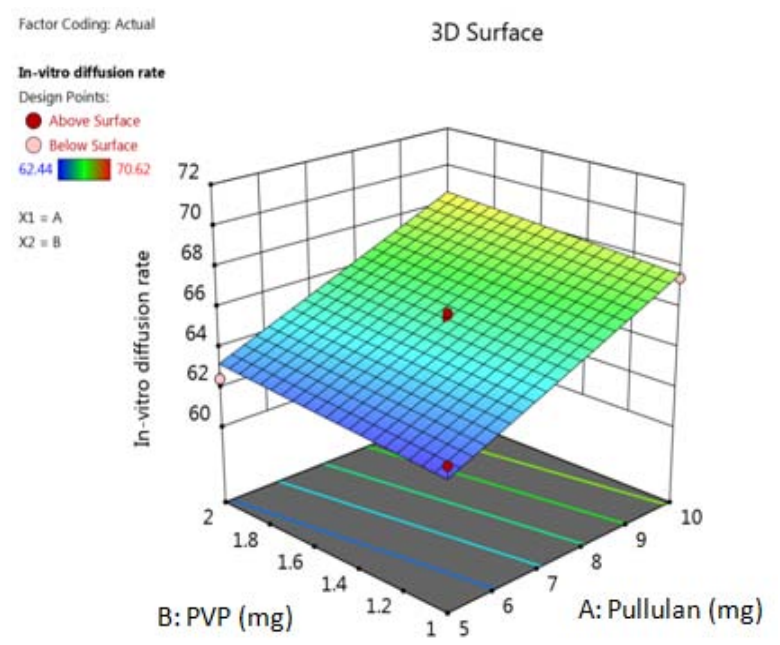

Fig. 8: Response surface plot showing the effect of variables on in vitro diffusion rate

Table 9: Evaluation of ocular insert of Besifloxacin (sandwich between two rate controlling membranes)

\begin{tabular}{llllll}
\hline Batch & Thickness (mm) & Weight variation (\% deviation) & \% Moisture absorption & \% Moisture loss & Surface pH \\
\hline F1 & $0.352 \pm 0.023$ & $0.32 \pm 0.039$ & $4.86 \pm 0.95$ & $5.42 \pm 0.68$ \\
F2 & $0.347 \pm 0.052$ & $0.45 \pm 0.081$ & $5.39 \pm 0.63$ & $7.12 \pm 0.43$ \\
F3 & $0.387 \pm 0.047$ & $0.63 \pm 0.067$ & $5.83 \pm 0.44$ & $7.28 \pm 0.39$ \\
F4 & $0.384 \pm 0.068$ & $0.57 \pm 0.053$ & $5.23 \pm 0.32$ & $7.42 \pm 0.58$ & $6.89 \pm 0.72$ \\
\hline
\end{tabular}

All values represent mean \pm standard deviation $(n=3)$ 


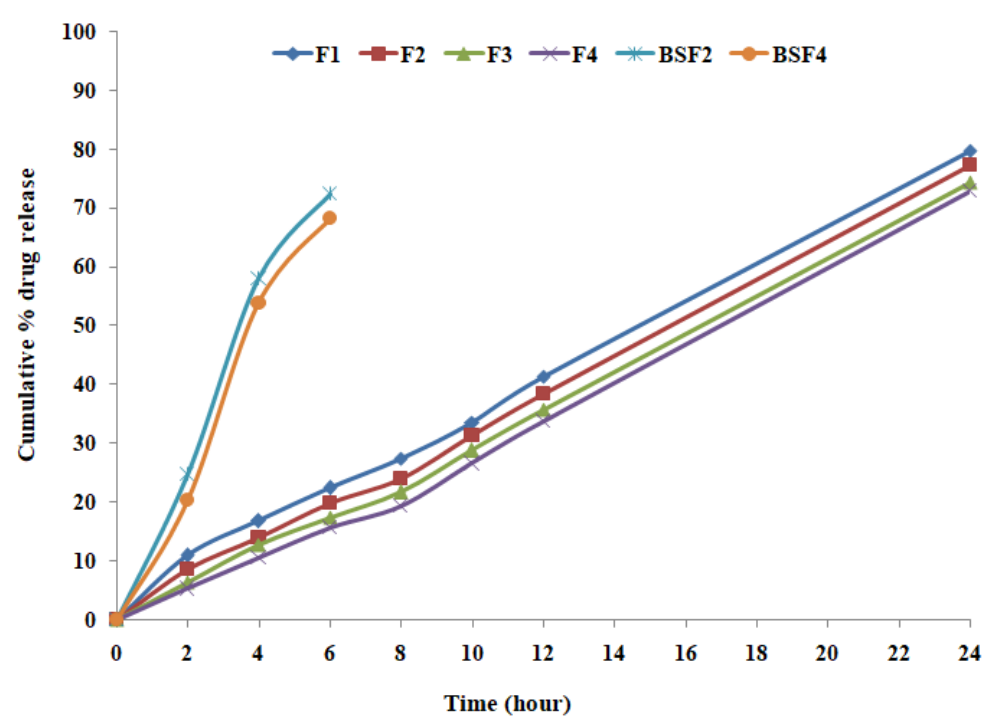

Fig. 9: In vitro diffusion of the ocular insert of Besifloxacin (sandwich between two rate-controlling membranes) and Reservoir formulation BSF2 to BSF4

Results showed that four formulations (F1 to F4) of ocular inserts of Besifloxacin sandwich between two rate-controlling membranes give sustained release of drug over $24 \mathrm{~h}$ as compared to reservoir formulation BSF2 to BSF4 [34].

\section{CONCLUSION}

From the present study, it can be concluded that physicochemical properties of inserts were found in a satisfactory range. The formulation BSF2 showed a maximum in vitro drug release profile, better-sustained action, and exhibited Korsmeyer-Peppas drug release kinetics (non-Fickian). Non-erodible ocular insert (formulation F4) consisting of Besifloxacin, $10 \mathrm{mg}$ of Pullulan, and 2 mg of polyvinyl pyrrolidone, sealed with Eudragit RS-100 ratecontrolling membrane (5\%), showed sustained release of the drug in the eye for $24 \mathrm{~h}$. Eudragit RS-100, as a sustained drug release polymer, showed promising sustained action. The formulations hence fulfilled all the pharmaceutical parameters of ocular inserts and appear to be promising, would be able to offer benefits such as increasing residence time, prolonging drug release, reducing the frequency of administration, and thereby may help to improve patient compliance.

\section{FUNDING}

Nil

\section{AUTHORS CONTRIBUTIONS}

All the authors have contributed equally.

\section{CONFLICT OF INTERESTS}

The authors declare that they have no conflict of interest.

\section{REFERENCES}

1. Høvding G. Acute bacterial conjunctivitis. Acta ophthalmol. 2008 Feb;86(1):5-17. doi: 10.1111/j.1600-0420.2007.01006.x, PMID 17970823.

2. Zhang JZ, Ward KW. Besifloxacin, a novel fluoroquinolone antimicrobial agent, exhibits potent inhibition of proinflammatory cytokines in human THP-1 monocytes. J Antimicrob Chemother. 2008 Jan 1;61(1):111-16. doi: 10.1093/jac/dkm398, PMID 17965029.

3. Tótoli EG, Salgado HRN. Besifloxacin: a critical review of its characteristics, properties, and analytical methods. Crit Rev Anal Chem. 2018 Mar 4;48(2):132-42. doi: 10.1080/10408347.2018.1429885, PMID 29345957.

4. Chang MH, Fung HB. Besifloxacin: a topical fluoroquinolone for the treatment of bacterial conjunctivitis. Clin Ther. 2010 Mar
1;32(3):454-71. doi: 10.1016/j.clinthera.2010.03.013, PMID 20399984.

5. Majithiya RJ, Ghosh PK, Umrethia ML, Murthy RS. Thermoreversible-mucoadhesive gel for nasal delivery of sumatriptan. AAPS PharmSciTech. 2006 Sep;7(3):67. doi: 10.1208/pt070367, PMID 17025248.

6. Dawaba AM, Dawaba HM, El-enin ASMA, Khalifa MKA. Fabrication of bioadhesive Ocusert with different polymers: once a day dose. Int J App Pharm. 2018 Nov 7;10(6):309-17. doi: 10.22159/ijap.2018v10i6.28495.

7. Mallari PL, McCarty DJ, Daniell M, Taylor H. Increased incidence of corneal perforation after topical fluoroquinolone treatment for microbial keratitis. Am J Ophthalmol. 2001 Jan 1;131(1):131-33. doi: 10.1016/s0002-9394(00)00642-5, PMID 11162991.

8. Gilhotra RM, Gilhotra N, Mishra DN. Piroxicam bioadhesive ocular inserts: physicochemical characterization and evaluation in prostaglandin-induced inflammation. Curr Eye Res. 2009 Dec 1;34(12):1065-73. doi: 10.3109/02713680903340738, PMID 19958126.

9. El-Gendy NA, Abdelbary GA, El-Komy MH, Saafan AE. Design and evaluation of a bioadhesive patch for topical delivery of gentamicin sulphate. Curr Drug Deliv. 2009 Jan 1;6(1):50-7. doi: 10.2174/156720109787048276, PMID 19418955.

10. RAO MV, Shyale S. Preparation and evaluation of ocular inserts containing norfloxacin. Turk J Med Sci. 2004 Jul 27;34(4):239-46.

11. Harikumar SL, Balasubramaniam J, Kumar MT, Pandit JK. In vitro characterization of physically reinforced ocular inserts of indomethacin. ACTA Pharm Sci. 2004;46(1).

12. Mundada AS, Shrikhande BK. Design and evaluation of soluble ocular drug insert for controlled release of ciprofloxacin hydrochloride. Drug Dev Ind Pharm. 2006 Jan 1;32(4):443-8. doi: 10.1080/03639040500534101, PMID 16638682.

13. Sreenivas SA, Hiremath SP, Godbole AM. Ofloxacin ocular inserts: design, formulation and evaluation. Iran J Pharmacol Ther. 2006 Dec 22;5(2):159-62.

14. Sankar V, Chandrasekaran AK, Durga S, Geetha G, Ravichandran V, Vijayakumar A, Raguraman S. Design and evaluation of diclofenac sodium ophthalmic inserts. Acta Pharm Sci. 2006;48(1).

15. El-Kamel A, Al-Dosari H, Al-Jenoobi F. Environmentally responsive ophthalmic gel formulation of carteolol hydrochloride. Drug Deliv. 2006 Jan 1;13(1):55-9. doi: 10.1080/10717540500309073, PMID 16401594.

16. Balasubramaniam J, Srinatha A, Nath G. In vitro microbiological evaluation of polyvinyl alcohol-based ocular inserts of ciprofloxacin hydrochloride. Indian J Pharm Sci. 2006;68(5). 
17. Jayaprakash S, Dachinamoorthi D, Ramkanth S, Nagarajan M, Sangeetha K. Formulation and evaluation of gentamicin sulphate ocuserts. Pharm Rev. 2006:131-4.

18. Mukherjee P, Manvi FV, Sreenivas SA. Sulphacetamide sodium ocular inserts: design, formulation and evaluation. Indian drugs-BOMBAY 2006;43(9):705.

19. Vijayendra Swamy SM, Nanjawade BK, Ravichandran M, Manvi FV. Development of sustained ocular drug delivery system for betaxolol. Indian J Pharm Educ Res. 2006;40(3):165.

20. Gupta A, Sharma SK, Ahuja M. In vitro and in vivo evaluation of gellan based ocular inserts of phenylephrine. Acta Pharm Sci. 2007;49(1)

21. Eaga CM. In-situ gels-a novel approach for ocular drug delivery. Pharm Lett. 2009;1:21-33.

22. Aburahma MH, Mahmoud AA. Biodegradable ocular inserts for sustained delivery of brimonidine tartarate: preparation and in vitro/in vivo evaluation. AAPS PharmSciTech. 2011 Dec;12(4):1335-47. doi: 10.1208/s12249-011-9701-3, PMID 21979886.

23. Juliano C, Cossu M, Pigozzi P, Rassu G, Giunchedi P. Preparation, in vitro characterization and preliminary in vivo evaluation of buccal polymeric films containing chlorhexidine. AAPS PharmSciTech. 2008;9(4):1153-8. doi: 10.1208/s12249-0089153-6, PMID 19015998.

24. Khan S, Ali A, Singhavi D, Yeole P. Controlled ocular delivery of acyclovir through rate-controlling ocular insert of eudragit: a technical note. AAPS PharmSciTech. 2008;9(1):169-73. doi: 10.1208/s12249-008-9032-1.

25. Niamprem PA, Srinivas SP, Tiyaboonchai WA. Development and characterization of indomethacin-loaded mucoadhesive nanostructured lipid carriers for topical ocular delivery. Int J App Pharm. 2018;10(2):91-6. doi: 10.22159/ijap.2018v10i2.24738.
26. Shankar V. A textbook of novel drug delivery system. Pharmamed press; 2012. p. 398-401.

27. Parmar RB, Tank HM. Design formulation and evaluation of reservoir type controlled released moxifloxacin hydrochloride ocular insert. Asian J Res Pharm Sci. 2013;3(1):19-24.

28. Kalyanwat R, Shrivastava B, Pathak K. Preparation and evaluation of bioadhesive ocular inserts of aceclofenac. Int J Pharm Sci Rev Res. 2016;41(2):207-13.

29. Jethava JK, Jethava GK. Design, formulation, and evaluation of novel sustain release bioadhesive in-situ gelling ocular inserts of ketorolac tromethamine. Int $\mathrm{J}$ Pharm Investig. 2014;4(4):226-32. doi: 10.4103/2230-973X.143131, PMID 25426444 .

30. Al-Saedi ZHF, Alzhrani RM, Boddu SHS. Formulation and in vitro evaluation of cyclosporine-a inserts prepared using hydroxypropyl methylcellulose for treating dry eye disease. J Ocul Pharmacol Ther. 2016;32(7):451-62. doi: 10.1089/jop.2016.0013, PMID 27294697.

31. Dhanaraju MD, Sivakumar VR, Subhashree R, Bhaskar K. Bioadhesive ocuserts matrix for ophthalmic administration of ciprofloxacin hydrochloride. Indian Drugs. 2002;39(4):222-4.

32. Khurana G, Arora S, Pawar PK. Ocular insert for sustained delivery of gatifloxacin sesquihydrate: preparation and evaluations. Int J Pharm Investig. 2012 Apr;2(2):70-7. doi: 10.4103/2230-973X.100040, PMID 23119235.

33. Gilhotra RM, Nagpal K, Mishra DN. Azithromycin novel drug delivery system for ocular application. Int J Pharm Investig. 2011;1(1):22-8. doi: 10.4103/2230-973X.76725, PMID 23071916.

34. Singh V, Bushetti SS, Raju SA, Ahmad R, Singh M, Ajmal M. Polymeric ocular hydrogels and ophthalmic inserts for controlled release of timolol maleate. J Pharm Bioallied Sci. 2011;3(2):280-5. doi: 10.4103/0975-7406.80773, PMID 21687359. 